Research Paper

\title{
Novel Powdered Anti-adhesion Material: Preventing Postoperative Intra-abdominal Adhesions in a Rat Model
}

\author{
Katsunori Takagi ${ }^{1}$, Masato Araki ${ }^{1}$, Hidetoshi Fukuoka ${ }^{1}$, Hiroaki Takeshita ${ }^{1}$, Shigekazu Hidaka ${ }^{1}$, Atsushi \\ Nanashima ${ }^{1}$, Terumitsu Sawai ${ }^{1}$, Takeshi Nagayasu${ }^{1}$, Suong-Hyu Hyon ${ }^{2}$, and Naoki Nakajima ${ }^{\circledR}$ \\ 1. Division of Surgical Oncology, Department of Translational Medical Sciences, Nagasaki University Graduate School of Biomedical \\ Sciences, Nagasaki, Japan; \\ 2. Department of Medical Simulation Engineering, Institute for Frontier Medical Sciences, Kyoto University, Kyoto, Japan.
}

$\triangle$ Corresponding author: Katsunori Takagi, Division of Surgical Oncology, Department of Translational Medical Sciences, Nagasaki University Graduate School of Biochemical Sciences, 1-7-1 Sakamoto, Nagasaki 852-8501, Japan. Phone: +81-95-819-7304; Fax: +81-95-819-7306

E-mail: spzq9r39@woody.ocn.ne.jp

(c) Ivyspring International Publisher. This is an open-access article distributed under the terms of the Creative Commons License (http://creativecommons.org/ licenses/by-nc-nd/3.0/). Reproduction is permitted for personal, noncommercial use, provided that the article is in whole, unmodified, and properly cited.

Received: 2012.11.27; Accepted: 2013.02.28; Published: 2013.03.05

\begin{abstract}
Background: Although laparoscopic surgery has decreased postoperative adhesions, complications induced by adhesions are still of great concern. The aim of this study was to investigate the anti-adhesive effects of a novel powdered anti-adhesion material that can be applied during laparoscopic surgery in comparison with other anti-adhesion materials. Methods: Our novel powdered anti-adhesion material is composed of aldehyde dextran and $\varepsilon$-poly(L-lysine). In 40 male rats, a $2.5 \times 2.0-\mathrm{cm}$ abdominal wall resection and cecum abrasion were performed. The rats were randomized into four groups based on the anti-adhesion treatments: normal saline; Seprafilm ${ }^{\circledR}$; Interceed ${ }^{\circledR}$; and novel powdered anti-adhesion material. The animals were euthanized on days 7 and 28 to evaluate the adhesion severity, area of adhesion formation, gross appearance, and pathological changes. Results: The adhesion severities on both days 7 and 28 were significantly lower for all anti-adhesion material groups compared with the normal saline group $(p<0.05)$. Pathologically, all groups showed inflammatory cell infiltration on day 7 and complete regeneration of the peritoneum on day 28. Conclusions: Our novel powdered anti-adhesion material was found to be effective for reducing postoperative intra-abdominal adhesions and showed equivalent efficacy to commercial anti-adhesion materials.
\end{abstract}

Key words: adhesion prevention, biodegradable material, powder, anti-adhesion materials, rat model.

\section{Introduction}

Adhesion formation is a common complication of abdominal surgery, with approximately $93 \%$ of patients developing intra-abdominal adhesions after abdominal surgery [1]. Adhesion formation causes symptomatic complications, such as small bowel obstruction, chronic pelvic pain, and infertility [2]. In addition, $5.7 \%$ of all readmissions are directly related to adhesions and $3.8 \%$ require further surgery [3], with the difficulty and duration of such surgeries being markedly increased $[4,5]$. Thus, patient quality of life is significantly affected by adhesion-related problems. The high recurrence rate of small bowel obstruction and the high cost of adhesion-related problems are serious issues [6,7].

The number of laparoscopic surgeries has increased in recent years. Laparoscopic cholecystectomy is able to reduce the formation of postoperative adhesions to $44.5 \%$, compared with $100 \%$ for open surgery [8]. In gynecologic operations, laparoscopic surgery is able to reduce the formation of postoperative adhe- 
sions to $19.8 \%$, compared with $51.7 \%$ for open surgery [9]. However, no reports have demonstrated its effects on the incidence of small bowel obstruction [10-12]. Postoperative adhesions remain a major problem, even with laparoscopic surgery.

Numerous anti-adhesion agents have been developed, but few are commercially available. Furthermore, only a few anti-adhesion agents can be used during laparoscopic surgery. Therefore, we developed a novel powdered anti-adhesion material (novel powder) that can be administered during laparoscopic surgery. Recently, this novel powder was used as a hydrogel glue sealant to prevent alveolar air leakage and as a drug vehicle to prevent graft infection in animal model studies $[13,14]$. In these studies, the novel powder showed good compatibility and did not cause severe inflammation that can lead to adhesion formation. Aldehyde dextrans are often used as crosslinkers in hydrogels, and their cytotoxicities are as low as $1 / 1000$ of the cytotoxicities of formaldehyde and glutaraldehyde. $\varepsilon$-Poly(L-lysine) is used as a food additive and its cytotoxicity is extremely low [15]. We newly developed an anti-adhesion material by changing the proportion rate of the aldehyde group of this material to control the degradation speed and make it suitable for an anti-adhesive function. We also changed the gel to a powder for administration under laparoscopic surgery. In this study, we investigated the anti-adhesive effects of our novel powder, in comparison with other commercially available anti-adhesion materials.

\section{Materials and Methods}

\section{Anti-adhesion materials}

The novel powder is composed of a Schiff base formation of aldehyde dextran and $\varepsilon$-poly(L-lysine) $[14,15]$. Briefly, $20 \mathrm{~g}$ of dextran $(70 \mathrm{kDa}$; Meiyo Sangyo Co., Ltd., Aichi, Japan) was dissolved in $80 \mathrm{ml}$ of distilled water. Two grams of sodium periodate dissolved in $40 \mathrm{ml}$ of water was then added to the dextran solution. Oxidation was allowed to proceed at $50^{\circ} \mathrm{C}$ for $1 \mathrm{~h}$, followed by dialysis and air-drying. Next, $0.5 \mathrm{~g}$ of succinic anhydride was added to $20 \mathrm{~g}$ of aqueous e-poly(L-lysine) (25 w/w\%, $4 \mathrm{kDa}$; Chisso Corp., Tokyo, Japan) and stirred at $50^{\circ} \mathrm{C}$ for $1 \mathrm{~h}$ to induce acylation. During the process of air-drying and crushing, \&-poly(L-lysine) was recovered with 12 $\mathrm{mol} \%$ of its amino groups acylated. Nine grams of aldehyde dextran (-CHO content $=0.23$ /sugar unit) and $1.0 \mathrm{~g}$ of $\varepsilon$-poly(L-lysine) powder were then mixed and crushed into a fine powder composed of granules of $<0.1 \mathrm{~mm}$. This powder could be immediately gelled by addition of water, requiring approximately 1 week to hydrolyze and degrade completely in vitro. The powder was administered via an application device made of glass and a rubber bulb (Fig. 1).

Seprafilm ${ }^{\circledR}$ (Genzyme Corporation, Cambridge, MA) and Interceed ${ }^{\circledR}$ (Ethicon, Inc., Somerville, NJ) were also used in this study for comparisons of the anti-adhesive effects.

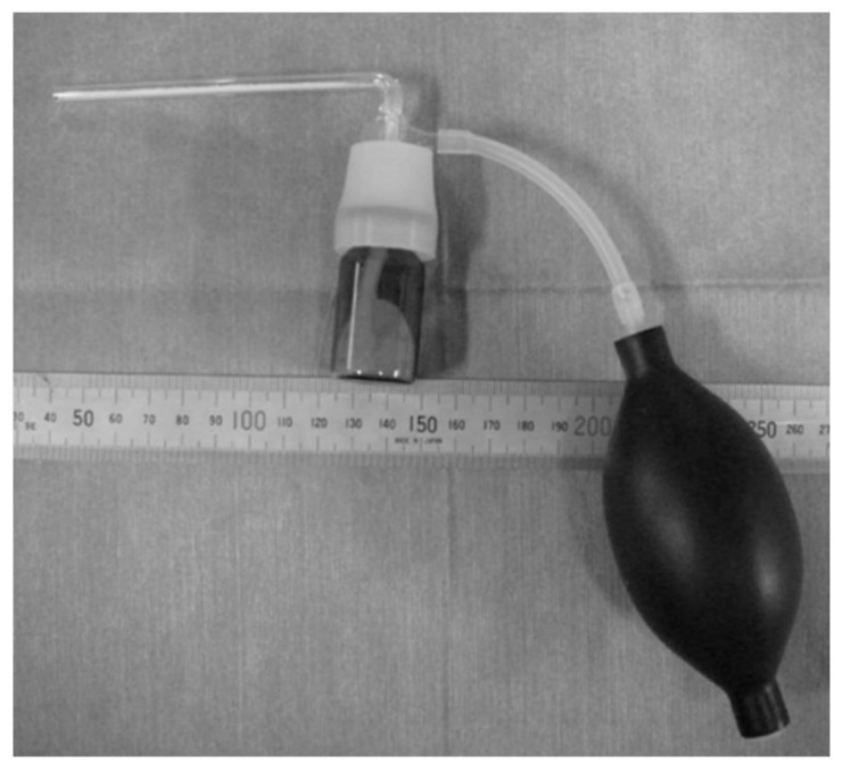

Fig I. Device used for application of the novel biodegradable powder.

\section{Animals}

Male Sprague-Dawley rats (Kyudo Corporation, Kumamoto, Japan) weighing 276-486 g and aged 8-12 weeks were used in this study. The animals were kept under standard conditions, fed standard rat food, and given tap water ad libitum. The Nagasaki University Graduate School of Biochemical Sciences Animal Experimentation Committee approved the experiments and all procedures were performed in accordance with the Animal Care Guidelines of the National Institutes of Health.

\section{Surgical procedure}

After inhalation of diethyl ether, the animals were anesthetized by intraperitoneal administration of $50 \mathrm{mg} / \mathrm{kg}$ pentobarbital sodium. Abdominal wall resection and cecal abrasion were performed as described elsewhere [16,17]. Briefly, the animals underwent a $5.0-\mathrm{cm}$ midline incision under sterile conditions. A $2.5 \times 2.0-\mathrm{cm}$ segment of the parietal peritoneum directly anterior to the cecum was excised sharply from the abdominal wall, including a superficial layer of the underlying muscle, at $1 \mathrm{~cm}$ lateral to the midline incision (Fig. 2A). The epigastric artery 
and vein were electrocauterized to minimize hemorrhaging. The defect was then abraded by 20 strokes of a toothbrush. The cecum was also abraded by 20 strokes of a toothbrush, such that a homogeneous surface of petechial hemorrhage was created (Fig. 2B). After the cecum was returned to the abdomen, the midline incision was closed in two layers with 5-0 vicryl and 5-0 nylon.

\section{Experimental design}

Animals were randomized into four subgroups, consisting of 10 rats each. In group I, approximately $1.0 \mathrm{ml}$ of normal saline was dropped into the abdominal cavity (control). In group II, a $3.0 \times 2.0-\mathrm{cm}$ piece of Seprafilm ${ }^{\circledR}$ was attached to the abdominal wall defect, immediately anterior to the abraded cecum (Fig. 2D). In group III, a $3.0 \times 2.0-\mathrm{cm}$ piece of Interceed ${ }^{\circledR}$ was attached to the abdominal wall defect, immediately anterior to the abraded cecum, and approximately $0.3 \mathrm{ml}$ of normal saline was added onto the Interceed ${ }^{\circledR}$ (Fig. 2E). In group IV, 0.2-0.3 g of novel powder was evenly spread on the abdominal wall defect, and then $0.2-0.3 \mathrm{ml}$ of normal saline was dropped onto the novel powder, which was then left for 2 min to harden (Fig. 2F).

Since many previous reports have chosen days 7 and 28 to evaluate the behaviors of anti-adhesion materials in the abdominal cavity and during the wound healing process of a damaged area [18-21], the animals were euthanized on days 7 and 28 after surgery to evaluate the adhesion severity, adhesion area, and gross and pathological appearances.

\section{Assessment of anti-adhesive effects}

The severity of adhesion formation was classified into six grades, as described elsewhere [17,22]: grade 0 , no adhesions; grade 1 , loose filmy adhesions that could be separated by blunt dissection; grade 2, adhesions requiring $<50 \%$ sharp dissection for separation; grade 3 , adhesions requiring $>50 \%$ sharp dissection for separation; grade 4 , serosal injury; and grade 5, full-thickness injury. The adhesion area was classified into four grades, as described elsewhere $[23,24]$ : grade 0 , none; grade $1, \leq 25 \%$ of area; grade 2 , $25-50 \%$ of area; and grade 3, 50-100\% of area. Evaluations of the adhesion severity and adhesion area were performed by a single surgeon who was blinded to the materials used for preventing adhesions.

\section{Pathological examination}

After evaluations of the adhesion severity and adhesion area for each anti-adhesion material on days 7 and 28, abdominal wall defect areas with no adhesions were excised and immersed in $10 \%$ formalin. Hematoxylin-eosin and Masson-trichrome staining were performed to evaluate the regeneration of the peritoneum and the foreign body reactions to the anti-adhesion materials.

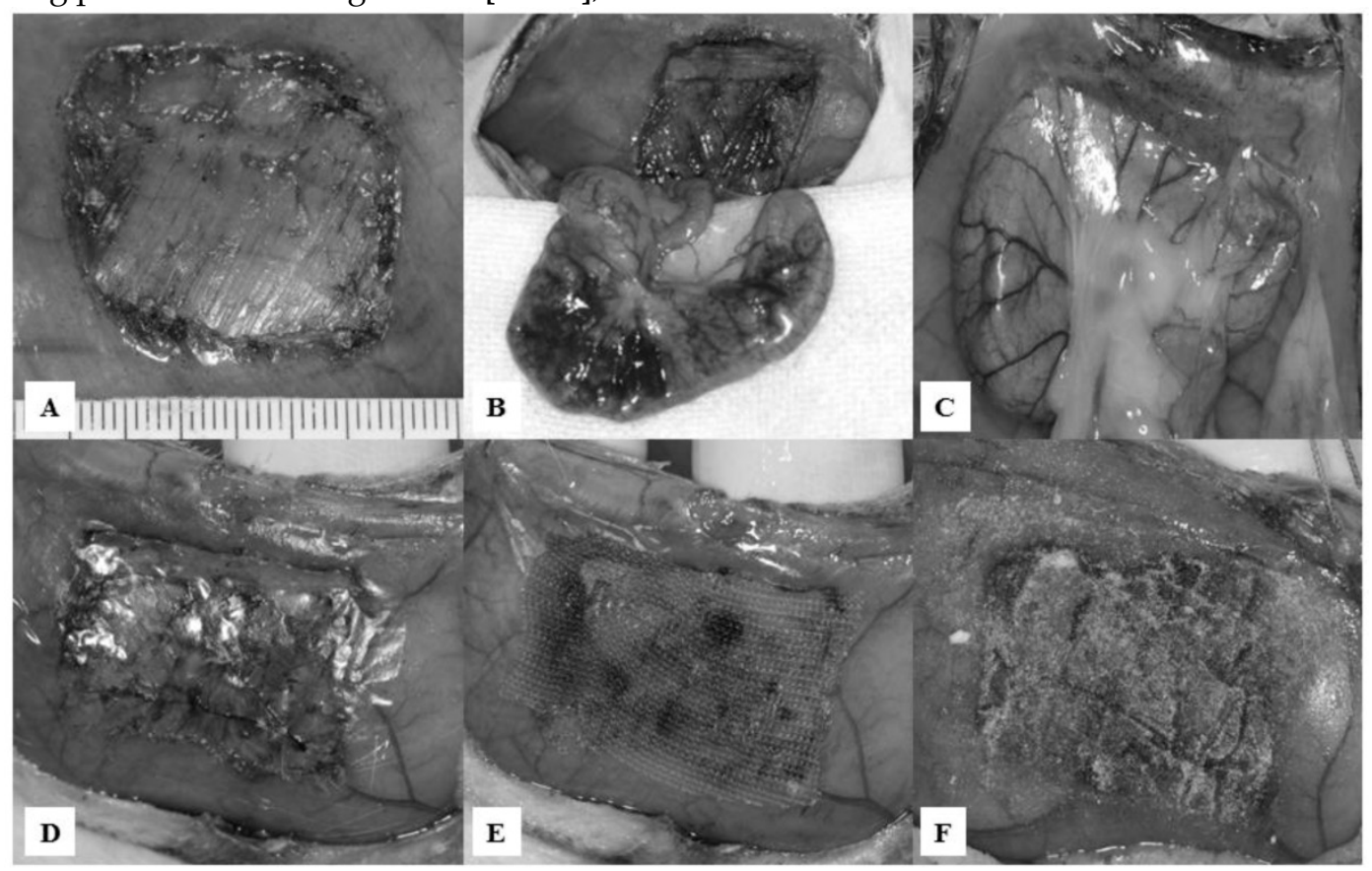

Fig 2. Appearances of the abdominal wall defect and cecum abrasion model, with application of anti-adhesion materials. A: A $2.5 \times 2.0-\mathrm{cm}$ abdominal wall defect, including a superficial layer of the underlying muscle, was created. B: The cecum was abraded using a toothbrush to induce petechial hemorrhaging. C: At 7 and 28 days after the initial surgery, all rats in group I (control) developed strong adhesion formation between the abraded cecum and the abdominal wall defect site. D: Appearance of group II. E: Appearance of group III. F: Appearance of group IV. 


\section{Statistical analysis}

StatView for Windows (SAS Institute, Cary, NC) and Microsoft Office Excel 2010 (Microsoft Corporation, Redmont, WA) were used for statistical analyses. The Kruskal-Wallis rank test and post-hoc comparisons (Scheffe and Steel-Dwass) were performed to compare the different treatments and determine $\mathrm{p}$-values for differences in the data. Values of $\mathrm{p}<0.05$ were considered to indicate statistical significance.

\section{Results}

There was no mortality caused by the anti-adhesion materials and none of the animals showed weight loss after the day of the initial surgery.

\section{Adhesions}

All rats in group I (control) showed severe adhesions between the abraded cecum and the abdominal wall defect sites (Fig. 2C). Fig. 3 shows the numbers of rats based on the adhesion severity grades and adhesion area grades in the four groups. The adhesion severity scores on day 7 were significantly lower in group IV (grades: $0, \mathrm{n}=1 ; 1, \mathrm{n}=4 ; 2, \mathrm{n}=0 ; 3$, $\mathrm{n}=0 ; 4, \mathrm{n}=0 ; 5, \mathrm{n}=0$ ), compared with group I (grades: 0 , $\mathrm{n}=0 ; 1, \mathrm{n}=0 ; 2, \mathrm{n}=4 ; 3, \mathrm{n}=1 ; 4, \mathrm{n}=0 ; 5, \mathrm{n}=0$ ) (Scheffe: $\mathrm{p}=0.0098$; Steel-Dwass: $\mathrm{p}=0.0274)$. The adhesion severity scores on day 28 were significantly lower in groups II (grades: $0, \mathrm{n}=0 ; 1, \mathrm{n}=5 ; 2, \mathrm{n}=0 ; 3, \mathrm{n}=0 ; 4, \mathrm{n}=0$; $5, \mathrm{n}=0$ ), III (grades: $0, \mathrm{n}=0 ; 1, \mathrm{n}=5 ; 2, \mathrm{n}=0 ; 3, \mathrm{n}=0 ; 4$, $\mathrm{n}=0 ; 5, \mathrm{n}=0$ ), and IV (grades: $0, \mathrm{n}=1 ; 1, \mathrm{n}=4 ; 2, \mathrm{n}=0 ; 3$, $\mathrm{n}=0 ; 4, \mathrm{n}=0 ; 5, \mathrm{n}=0$ ), compared with group I (grades: 0 , $\mathrm{n}=0 ; 1, \mathrm{n}=0 ; 2, \mathrm{n}=0 ; 3, \mathrm{n}=1 ; 4, \mathrm{n}=4 ; 5, \mathrm{n}=0$ ) (Scheffe: $\mathrm{p}=0.0193, \mathrm{p}=0.0193$, and $\mathrm{p}=0.0041$, respectively; Steel-Dwass: $p=0.0203, p=0.0203$, and $p=0.0274$, respectively). There were no significant differences among groups II, III, and IV on either day 7 or day 28 . The adhesion area scores on both days 7 and 28 were higher in group I than in the other groups, but there were no significant differences among the groups.
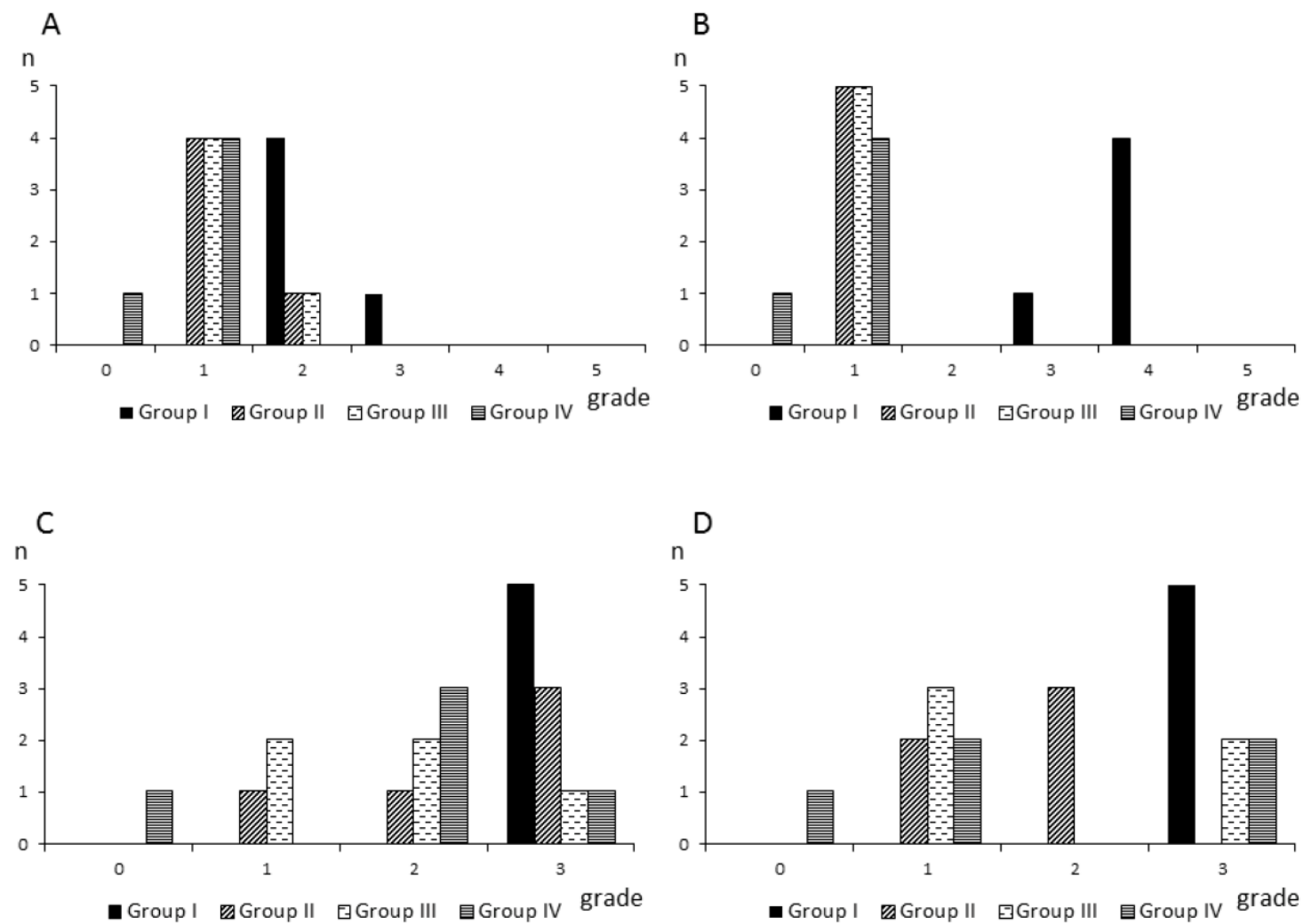

Fig 3. Numbers of rats based on the adhesion severity scores and adhesion area scores in each group. $A, B$ : Numbers of rat based on the adhesion severity score grades on day 7 (A) and day 28 (B) in each group. C,D: Numbers of rats based on the adhesion area score grades on day $7(C)$ and day $28(D)$ in each group. 


\section{Gross and pathological appearances}

On day 7, group II (Seprafilm ${ }^{\circledR}$ ) showed loose filmy adhesions, and the abdominal wall defect sites were partly covered with thick white tissue (Fig. 4A). A pathological study showed multilayered inflammatory cells in the abdominal wall defect sites (Fig. $4 B, C)$. Group III (Interceed ${ }^{\circledR}$ ) showed loose filmy adhesions and thick brownish-red tissue on the abdominal wall defect sites (Fig. 4D). A pathological study revealed inflammatory cells, such as lymphocytes and fibroblasts, on the abdominal wall defect sites (Fig. 4E,F). In group IV (novel powder), the abdominal wall defect sites were partly covered with thick white tissue (Fig. 4G). Similar to group II, a pathological study showed multiple layers of inflammatory cells (Fig. 4H,I). In all groups, there were no differences with regard to the pathological appearance, but the thickness of the inflammatory cells was greater in group III.

On day 28, group II showed loose filmy adhesions (Fig. 5A). A pathological study showed completely regenerated mesothelial cells (Fig. 5B,C).

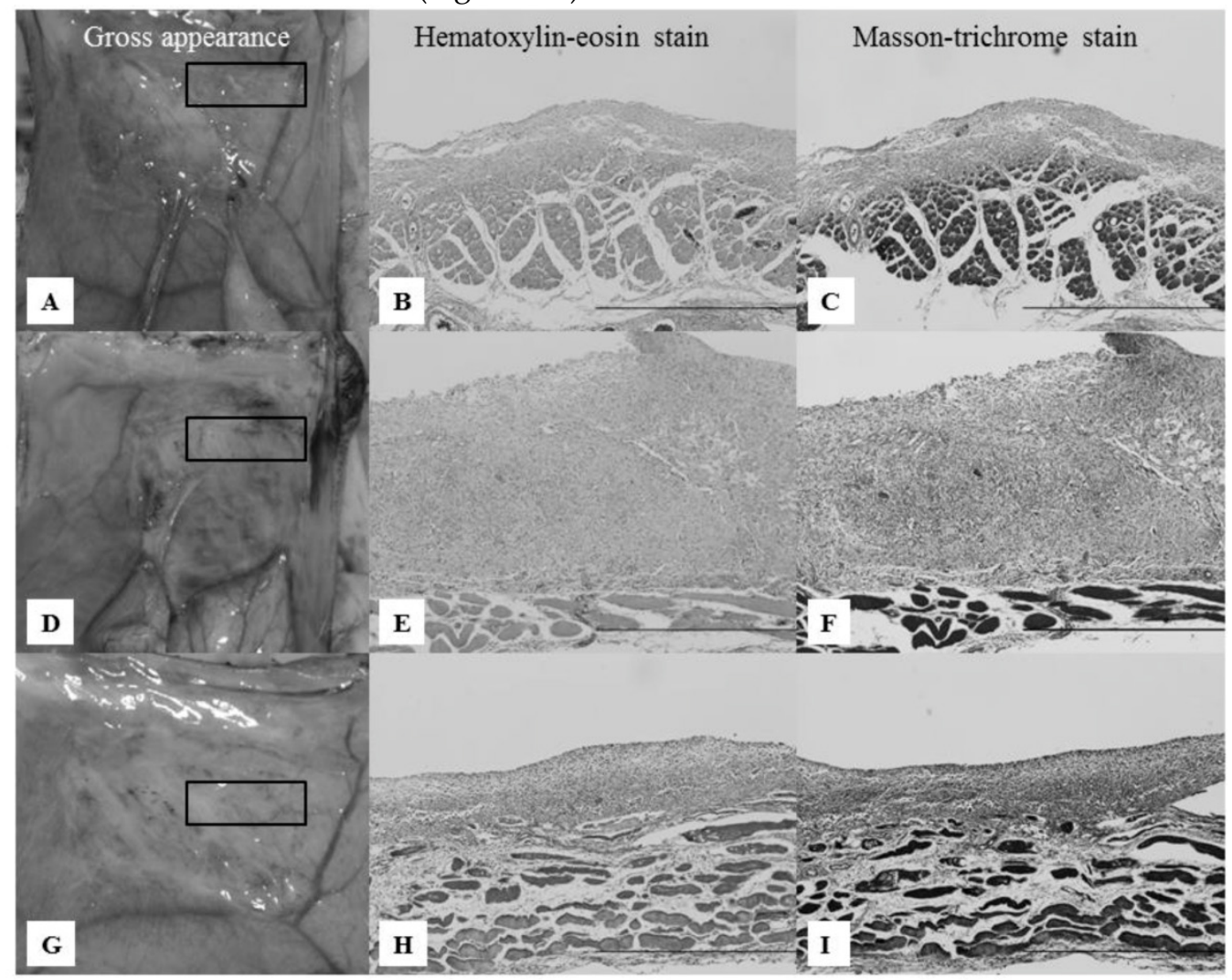

Fig 4. Gross and pathological appearances of the abdominal wall defect sites on day 7 . All microscopic images correspond to the rectangles in the gross appearance images on the left, focusing on the border of the abdominal muscle to which the anti-adhesion materials were applied. Scale bars: $100 \mu \mathrm{m}(\times 40)$. A-C: Gross and pathological appearances of group II. Loose filmy adhesions with thick white tissue and multilayered inflammatory cells were seen on the abdominal wall defect sites. D-F: Gross and pathological appearances of group III. Loose filmy adhesions with thick brownish-red tissue and multilayered inflammatory cells were seen on the abdominal wall defect sites. Inflammatory cells were thicker compared with groups II and IV. G-I: Gross and pathological appearances of group IV. Considerably loose filmy adhesions, white tissue, and inflammatory cells were seen, similar to group II.
Group III showed loose adhesions (Fig. 5D). Similar to group II, completely regenerated mesothelial cells were seen on the abdominal wall defect sites (Fig. $5 \mathrm{E}, \mathrm{F})$. Group IV showed complete regeneration of mesothelial cells on the abdominal wall defect sites (Fig. 5G).

All groups other than group I showed abdominal wall defect sites covered with thin and transparent layers. Thick white or brownish-red tissue was not seen at these sites. A pathological study revealed regenerated mesothelial cells in the abdominal among the anti-adhesion materials.

In the non-adhesion areas of the abraded cecum, we did not observe any changes in the gross appearance compared with the non-abraded cecum near the abraded cecum sites on either day 7 or day 28. A pathological study revealed that the mesothelial cells composing the cecal serosa had fully regenerated. There were no differences among the anti-adhesion materials. wall defect sites. There were no obvious differences 


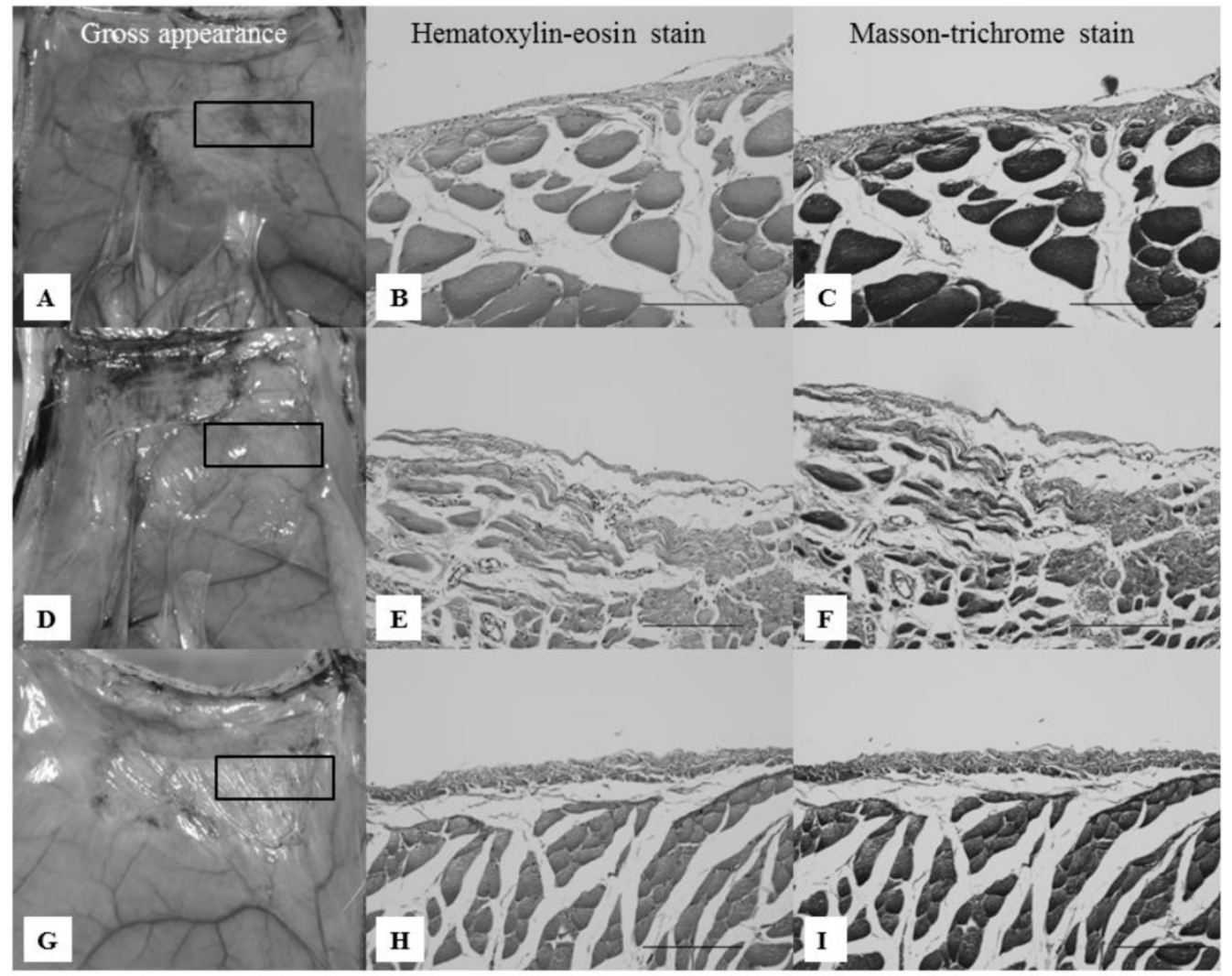

Fig 5. Gross and pathological appearances of the abdominal wall defect sites on day 28. All microscopic images correspond to the rectangles in the gross appearance images on the left, focusing on the border of the abdominal muscle to which the anti-adhesion materials were applied. Scale bars: $20 \mu \mathrm{m}(\times 100)$. A-C: Gross and pathological appearances of group II. Loose filmy adhesions and completely regenerated mesothelial cells were seen on the abdominal wall defect sites. D-F: Gross and pathological appearances of group III. Loose filmy adhesions and completely regenerated mesothelial cells were seen on the abdominal wall defect sites, similar to group II. G-I: Gross and pathological appearances of group IV. Considerably loose filmy adhesions and complete regeneration of the mesothelial cells were seen on the abdominal wall defect sites, similar to groups II and III.

\section{Discussion}

Research to date has confirmed three main methods for preventing the formation of postoperative adhesions [10]: reduction of peritoneal trauma by using minimally invasive surgical procedures, such as laparoscopic surgery; prevention of fibrin formation with pharmacological agents, such as heparin or tissue plasminogen activator; and reducing contact between organs and intra-abdominal contents by using biodegradable barriers such as Seprafilm ${ }^{\circledR}$. Of these approaches, the use of biodegradable barriers is the best studied. However, no single approach has been wholly satisfactory in reducing adhesions [25].

The widely used and commercially available anti-adhesion materials at present include Seprafilm ${ }^{\circledR}$, Interceed ${ }^{\circledR}$, and Adept $^{\circledR}$. Seprafilm ${ }^{\circledR}$ and Interceed ${ }^{\circledR}$ are sheet-type anti-adhesion materials composed of carboxymethylcellulose, sodium hyaluronate, and oxidized regenerated cellulose [26-28]. Adept ${ }^{\circledR}$ is a liquid-type anti-adhesion material composed of $4 \%$ icodextrin [29]. The anti-adhesive effects of these ma- terials have been demonstrated, but they have been associated with problems.

Seprafilm ${ }^{\circledR}$ has been associated with anastomotic leakage $[26,27]$. Furthermore, Seprafilm ${ }^{\circledR}$ is difficult to place in the peritoneal cavity because the sheets are not deformable and readily become stuck when wet. After these films become stuck in an inappropriate location, they are difficult to move to the correct position. To overcome these issues, surgeons have created unique methods for administering Seprafilm ${ }^{\circledR}$ into the abdominal cavity via a laparoscopic trocar [30-32]. However, these approaches are not addressed in the product labeling, and require much time and effort. Interceed ${ }^{\circledR}$ can be used in laparoscopic surgery, but has reduced anti-adhesive effects in the presence of blood and is easily moved because of its lower adhesive qualities [18]. These weak adhesive qualities may result in Interceed ${ }^{\circledR}$ sheets moving away from the correct location. Adept ${ }^{\circledR}$ can also be used in laparoscopic surgery, but causes abdominal discomfort and abdominal distension as a result of its administration dosage $(1,000 \mathrm{ml})$ [29]. 
We developed a powdered anti-adhesion material to resolve these issues. Although powder application under pneumoperitoneum may appear difficult, several reports have described powder application methods [33,34]. Fossum et al. [33] used a delivery instrument made of a bulb and a nozzle, resembling our application device, which makes it easy to administer powdered materials even under pneumoperitoneum.

For prevention of adhesion formation in various fields of surgery, a powdered material has two advantages compared with sheet and liquid materials. First, a powder can be administered in both open and laparoscopic surgery settings. Administration of the novel powder via a laparoscopic trocar using longer nozzles would be as simple and accurate as using other laparoscopic forceps. Furthermore, the novel powder can be administered to all regions that can be reached by the nozzles, even in the pelvic cavity. However, further studies are necessary to evaluate laparoscopic devices for powder application. Second, only a minimal dose is necessary, because it is easy to administer the powder locally at the desired site to prevent adhesion formation.

Postoperative adhesion formation has been characterized as an excess fibrin deposition resulting from an imbalance between fibrin deposition and fibrin degradation. The excess fibrin deposition forms a fibrin bridge between injured tissues and neighboring organs. Adhesion formation occurs within the first few days after surgery, with reperitonealization starting at $24 \mathrm{~h}$ and finishing at 7-10 days after the initial surgery or injury. Therefore, the ideal anti-adhesion material needs to preserve the structure for 1 week [35]. Seprafilm ${ }^{\circledR}$ and Interceed ${ }^{\circledR}$ are both known to remain at the target site for approximately 1 week. Thus, 1 week for complete hydrolyzation is a practical degradation speed for anti-adhesion materials.

In the present study, multiple layers of inflammatory cells and a few mesothelial cells were observed in all groups on day 7 , while the anti-adhesion materials had largely disappeared. On day 28, all groups showed complete regeneration of the mesothelial cells composing the peritoneum. There were no differences in the wound healing process among the commercial anti-adhesion materials and the novel powder. In addition, group I showed strong adhesion severity on day 28 , compared with day 7 . Since adhesion severity increases gradually after adhesion formation, it is important to prevent the adhesion formation as early as possible [35].

The adhesion model used in this study involves the induction of petechial hemorrhage from the abraded cecum. The fact that the differences among the anti-adhesion materials were not significant with regard to the adhesion scores suggests that hemorrhaging adversely affects Interceed ${ }^{\circledR}$, as previously reported [18], as well as Seprafilm ${ }^{\circledR}$ and the novel powder. Group III demonstrated thick brownish-red tissue on the abdominal wall defect sites, and a pathological study of this tissue revealed more inflammatory cells compared with the other materials. The brownish-red color was caused by the presence of hemostasis from the abraded cecum [36]. As Interceed $^{\circledR}$ itself is thicker than Seprafilm ${ }^{\circledR}$ and the novel powder, the residuum of Interceed ${ }^{\circledR}$ on day 7 was thicker than those of the other materials. The foreign body response to Interceed ${ }^{\circledR}$ may have been stronger than those to Seprafilm ${ }^{\circledR}$ or the novel powder. This could explain why the layer of inflammatory cells was thicker with Interceed ${ }^{\circledR}$ than with the other anti-adhesion materials. The present results in the abdominal cavity suggest that this variation in the level of inflammatory cells did not have much influence on the adhesion severity.

In conclusion, our novel powder showed equivalent efficacy to other commercially available anti-adhesion materials. Pathologically, it was completely degraded within 1 week. This novel biodegradable powder has the potential to reduce postoperative adhesions, even in laparoscopic surgery.

\section{Competing Interests}

The authors have declared that no competing interest exists.

\section{References}

1. Menzies D, Ellis H. Intestinal obstruction from adhesions--how big is the problem? Ann R Coll Surg Engl 1990; 72: 60-3.

2. Vrijland WW, Jeekel J, van Geldorp HJ, et al. Abdominal adhesions: intestinal obstruction, pain, and infertility. Surg Endosc 2003; 17: 1017-22.

3. Ellis H, Moran BJ, Thompson JN, et al. Adhesion-related hospital readmissions after abdominal and pelvic surgery: a retrospective cohort study. Lancet 1999; 353: 1476-80.

4. van Der Krabben AA, Dijkstra FR, Nieuwenhuijzen M, et al. Morbidity and mortality of inadvertent enterotomy during adhesiotomy. Br J Surg 2000; 87: 467-71.

5. van Goor H. Consequences and complications of peritoneal adhesions. Colorectal Dis 2007; 9 Suppl 2: 25-34.

6. Duron JJ, Silva NJ, du Montcel ST, et al. Adhesive postoperative small bowel obstruction: incidence and risk factors of recurrence after surgical treatment: a multicenter prospective study. Ann Surg 2006; 244: 750-7.

7. Tingstedt B, Isaksson J, Andersson R. Long-term follow-up and cost analysis following surgery for small bowel obstruction caused by intra-abdominal adhesions. Br J Surg 2007; 94: 743-8.

8. Polymeneas G, Theodosopoulos T, Stamatiadis A, et al. A comparative study of postoperative adhesion formation after laparoscopic vs open cholecystectomy. Surg Endosc 2001; 15: 41-3.

9. Audebert AJ, Gomel V. Role of microlaparoscopy in the diagnosis of peritoneal and visceral adhesions and in the prevention of bowel injury associated with blind trocar insertion. Fertil Steril 2000; 73: 631-5.

10. Tingstedt B, Isaksson K, Andersson E, et al. Prevention of abdominal adhesions-present state and what's beyond the horizon? Eur Surg Res 2007; 39: 259-268 
11. Ray NF, Denton WG, Thamer M, et al. Abdominal adhesiolysis: inpatient care and expenditures in the United States in 1994. J Am Coll Surg 1998; 186: $1-9$.

12. Gutt $\mathrm{CN}$, Oniu $\mathrm{T}$, Schemmer $\mathrm{P}$, et al. Fewer Adhesions induced by laparoscopic surgery? Surg Endosc 2004; 18: 898-906.

13. Araki M, Tao H, Nakajima N, et al. Development of new biodegradable hydrogel glue for preventing alveolar air leakage. J Thorac Cardiovasc Surg. 2007; 134: 1241-8.

14. Morishima M, Marui A, Yanagi S, et al. Sustained release of vancomycin from a new biodegradable glue to prevent methicillin-resistant Staphylococcus aureus graft infection. Interact Cardiovasc Thorac Surg 2010; 11: $52-5$.

15. Nakajima N, Sugai H, Tsutsumi $S$, et al. Self-degradable bioadhesive. Key Eng Mater 2007; 342-343:713-6.

16. Harris ES, Morgan RF, Rodeheaver GT. Analysis of the kinetics of peritoneal adhesion formation in the rat and evaluation of potential antiadhesive agents. Surgery 1995; 117: 663-9.

17. Izumi Y, Yamamoto M, Kawamura M, et al. Cross-linked poly (gamma-glutamic acid) attenuates peritoneal adhesion in a rat model. Surgery 2007; 141: 678-81.

18. Wiseman DM, Gottlick-Iarkowski L, Kamp L. Effect of different barriers of oxidized regenerated cellulose (ORC) on cecal and sidewall adhesions in the presence and absence of bleeding. J Invest Surg 1999; 12: 141-46.

19. Tulandi T, Agdi M, Zarei A, et al. Adhesion development and morbidity after repeat cesarean delivery. Am J Obstet Gynecol 2009; 201: 56.e1-6.

20. Lim R, Morrill JM, Lynch RC, et al. Practical limitations of bioresorbable membranes in the prevention of intra-abdominal adhesions. J Gastrointest Surg 2009; 13: 35-41.

21. Felemovicius I, Bonsack ME, Hagerman G, et al. Prevention of adhesions to polypropylene mesh. J Am Coll Surg 2004; 198: 543-8.

22. Oncel M, Remzi FH, Senagore AJ, et al. Comparison of a novel liquid (Adcon-P) and a sodium hyaluronate and carboxymethylcellulose membrane (Seprafilm) in postsurgical adhesion formation in a murine model. Dis Colon Rectum 2003; 46: 187-91.

23. Duran B, Ak D, Cetin A, et al. Reduction of postoperative adhesions by $\mathrm{N}, \mathrm{O}$-carboxymethylchitosan and spermine NONOate in rats. Exp Anim 2003; 52: 267-72.

24. Condon ET, Cahill RA, O'malley DB, et al. Evaluation of postoperative peritoneal adhesion formation following perioperative nicotine administration. J Surg Res 2007; 140: 135-8.

25. Lauder CI, Garcea G, Strickland A, et al. Abdominal adhesion prevention: still a sticky subject? Dig Surg 2010; 27: 347-58.

26. Fazio VW, Cohen Z, Fleshman JW, et al. Reduction in adhesive small-bowel obstruction by Seprafilm adhesion barrier after intestinal resection. Dis Colon Rectum 2005; 49: 1-11.

27. Beck DE, Cohen Z, Fleshman JW, et al. A prospective, randomized, multicenter, controlled study of the safety of seprafilm adhesion barrier in abdominopelvic surgery of the intestine. Dis Colon Rectum 2003; 46: 1310-29.

28. Wiseman DM, Trout JR, Franklin RR, et al. Meta-analysis of the safety and efficacy of an adhesion barrier (Interceed TC7) in laparotomy. J Reprod Med 1999; 44: 325-31.

29. Menzies D, Pascual MH, Walz MK, et al. Use of icodextrin $4 \%$ solution in the prevention of adhesion formation following general surgery: from the multicentre ARIEL Registry. Ann R Coll Surg Engl 2006; 88: 375-82.

30. Ortiz MV, Awad ZT. An easy technique for laparoscopic placement of Seprafilm. Surg Laparosc Endosc Percutan Tech 2009; 19: 181-3.

31. Shinohara T, Kashiwagi $H$, Yanagisawa $S$, et al. A simple and novel technique for the placement of antiadhesive membrane in laparoscopic surgery. Surg Laparosc Endosc Percutan Tech 2008; 18: 188-191.

32. Chuang YC, Fan CN, Cho FN, et al. A novel technique to apply a Seprafilm (hyaluronate-carboxymethylcellulose) barrier following laparoscopic surgeries. Fertil Steril 2008; 90: 1959-63.

33. Fossum GT, Silverberg KM, Miller CE, et al. Gynecologic use of Sepraspray Adhesion Barrier for reduction of adhesion development after laparoscopic myomectomy: a pilot study. Fertil Steril 2011; 96: 487-91.

34. Bishoff JT, Cornum RL, Perahia B, et al. Laparoscopic heminephrectomy using a new fibrin sealant powder. Urology 2003; 62: 1139-43.

35. Boland GM, Weigel RJ. Formation and prevention of postoperative abdominal adhesions. J Surg Res 2006; 132: 3-12.

36. Bates GW Jr, Shomento S. Adhesion prevention in patients with multiple cesarean deliveries. Am J Obstet Gynecol 2011; 205: S19-24. 